\title{
Atuação dos aparelhos privados de hegemo- nia na implementação da BNCC nos estados da Região Sul
}

\author{
Marilda Pasqual Schneider \\ Camila Regina Rostirola \\ Universidade do Oeste de Santa Catarina (Brasil)
}

\section{Resumo}

texto tem por objetivo analisar as propostas curriculares dos sistemas estaduais dos três estados da Região Sul, realçando os procedimentos adotados para adequação das propostas curriculares estaduais à BNCC e o papel do Movimento Pela Base Nacional Comum enquanto um aparelho privado de hegemonia, na produção de constrangimentos às recontextualizações produzidas pelas redes de ensino. Ancora-se nos pressupostos da pesquisa qualitativa, tendo como recurso analítico o levantamento e a análise de dados documentais. À guisa de conclusão, realçamos os desafios às instituições de ensino na materialização de um currículo que garanta atendimento às funções sociais da educação.

Palavras-chave: Governança em rede. Movimento Pela Base Nacional Comum. Base Nacional Comum Curricular. Aparelhos privados de hegemonia.

\section{The role of private hegemonic apparatuses in the implementation of the BNCC in the states of the Southern Region}

\footnotetext{
Abstract

The text aims to analyze the curriculum proposals of the state teaching systems of the three states of the Southern Region, highlighting the procedures undertaken to adjust the state curriculum proposals to the Common National Curricular Base (BNCC, in Portuguese abbreviation) and the role of the Movement for the National Common Base, as a private hegemonic apparatus, in the production of constraints to the recontextualizations produced by the education networks. It is anchored in the assumptions of qualitative research, using as an analytical resource the survey and analysis of documentary data. As a conclusion, we highlight the challenges to educational institutions in the materialization of a curriculum that ensures the fulfillment of the social functions of education.

Keywords: Network governance. Movement for the Common National Base. Common National Curricular Base. Private hegemonic apparatus.
} 
Atuação dos aparelhos privados de hegemonia na implementação da BNCC nos estados da Região Sul

\section{La actuación de los aparatos hegemónicos privados en la implementación del BNCC en los estados de la Región Sur}

\section{Resumen}

El texto tiene como objetivo analizar las propuestas curriculares de los sistemas estatales de enseñanza de los tres estados de la Región Sur, destacando los procedimientos adoptados para adecuar las propuestas curriculares estatales a la Base Nacional Curricular Común (BNCC) y el rol del Movimiento por la Base Nacional Común, como aparato hegemónico privado, en la producción de limitaciones a las recontextualizaciones producidas por las redes de enseñanza. Se ancla en los supuestos de la investigación cualitativa, utilizando como recurso analítico la encuesta y el análisis de datos documentales. Como conclusión, se destacan los desafíos a las instituciones educativas en la materialización de un currículo que asegure el cumplimiento de las funciones sociales de la educación.

Palabras clave: Gobernanza en red. Movimiento por la Base Nacional Común. Base Curricular Común Nacional. Aparatos hegemónicos privados.

\section{Introdução}

Especialistas do campo do curricular, tais como Apple (1989; 2006; 2008), Goodson (1997; 1999; 2007; 2010), Lopes e Macedo (2011), Pacheco (2005), Popkewitz (2011), Silva (2002), entre outros, têm evidenciado que a definição do conceito de currículo escolar não constitui tarefa fácil. Concordam, porém, que se trata de uma fabricação social (GOODSON, 2001 l) situada em um território em constante disputa (APPLE, 1989; 2008) na qual predominam forças dialéticas de poder e governança (POPKEWITZ, 2011 ) com uma constante luta políitica pela significação do que vem a ser currículo (LOPES; MACEDO, 201 1) consoante às finalidades educacionais pretendidas em certo contexto histórico-social, cultural e econômico.

As tensões em torno de uma determinada visão e, por consequência, de um texto escolar, resultam dos interesses em jogo e dos estratagemas forjados no espaço do Estado para tornar hegemônica uma concepção de currículo. A esse respeito, Apple afirma:

[...] é preciso levar muito a sério que este é um tempo em que as visões, os pressupostos e compromissos ideológicos da direita estão presentes de forma poderosa, estão bem financiados, e cada 
vez se tornam partes centrais do senso comum dominante em muitas nações do mundo inteiro (APPLE, 2017, p. 902).

É certo que a disputa pela hegemonia em torno de um conhecimento válido não se dá descolada da atuação do Estado. Tomando como ponto de partida a análise efetuada sobre as contribuições de Michael Apple para o campo da pesquisa em políticas educacionais, Gandin e Lima (2016, p. 655) destacam que o Estado é um local de disputa "[...] no qual diferentes blocos lutam para serem hegemônicos e também para tornarem suas ideias hegemônicas". Enquanto espaço de disputas e alianças, as políticas emanadas do Estado não resultam exclusivamente das decisões daqueles que o representam, mas de acordos e concessões formulados entre e no interior de grupos com interesses distintos e que atuam tanto dentro como fora do Estado.

Apple (2003, p. 10) argumenta que, no atual contexto globalizante, está a surgir uma nova direita constituída por neoliberais, neoconservadores, populistas autoritários e pela nova classe média profissional. Nas últimas décadas, esses grupos lançaram um ataque conjunto "[...] sobre o que muitos de nós consideravam natural". Embora toda a esfera pública tenha sido posta em questão, os ataques às instituições educacionais [...] têm ocupado um lugar central nas críticas direitistas". Trata-se de um projeto societal e ideológico de grandes proporções, para o qual se requer a coalização de forças que tanto podem ser comuns como conflitantes entre si.

No Brasil, os grupos que fazem parte da nova direita brasileira vêm sendo cunhados de "aparelhos privados de hegemonia" (BUCCI-GLUKSMANN, 1980; GUIDO-LIGUORI, 2007; BIANCHI, 2008; FONTES, 2010; MENDONCCA, 2014; HOEVELER, 2019). Trata-se de um conceito gramsciano utilizado heuristicamente por cientistas sociais para designar as instituições, os espaços ou os agentes que se envolvem em projetos sociais e ideológicos "[...] de grandes proporções" (APPLE, 2003, p. 10). São assim designados porque sua atuação tanto pode ocorrer dentro de uma determinada classe social ou em aliança com classes distintas, atravessando, pois, "[...] as fronteiras do chamado público (pertencente ao Estado) e privado (sociedade civil)" (HOEVELER, 2019, p. 153). Embora sua materialização se dê por meio dos aparelhos da burguesia, progressivamente alguns destes grupos passam a integrar o Estado. De acordo com Casimiro (2018), os aparelhos privados de hegemonia brasileiros são organizações que 
Atuação dos aparelhos privados de hegemonia na implementação da BNCC nos estados da Região Sul

[...] atuam tanto no sentido doutrinário - de difusão de diferentes matrizes do pensamento liberal e recrutamento de intelectuais orgânicos - quanto no campo considerado mais pragmático de elaboração de diretrizes, intervenção e proposição de políticas públicas, e de ação estrutural, a licerçada em um projeto de poder, desenvolvendo estratégias por dentro do Estado (CASIMIRO, 2018, p. 18).

Essas organizações são constituídas por grupos de intelectuais coletivos e representantes políticos de segmentos da direita liberal cujo propósito central consiste em produzir consensos em torno de projetos derivados de aparelhos distintos, ainda que, conforme Mendonça (2014, p. 36), "[...] em muitos casos, pertençam a uma mesma classe ou fração dela."

Assente na ideia de que o campo do currículo se encontra permeado por interesses de aparelhos privados de hegemonia, admitimos que a decisão sobre a necessidade de uma Base Nacional Comum Curricular (BNCC) para todas as escolas de educação básica do País, assim como a elaboração da versão final do documento que a informa e a traduz, resultaram das lutas arquitetadas por alguns desses aparelhos.

É, pois, no contexto esboçado que pretendemos situar o debate sobre a governança em rede e o papel assumido por alguns aparelhos privados de hegemonia na construção de uma hegemonia do discurso pedagógico construído pelas redes de governança que ofereceram sustentação à implantação da BNCC. Nessa direção, o texto tem por objetivo analisar propostas curriculares de sistemas estaduais dos três estados da Região Sul, realçando procedimentos no processo de adequação das propostas curriculares estaduais à BNCC e o papel assumido pelo Movimento Todos Pela Base Nacional Comum (MBNC), enquanto um aparelho privado de hegemonia, na produção de constrangimentos às interpretações dos currículos dos estados da federação.

$\bigcirc$ estudo ancora-se nos pressupostos da pesquisa qualitativa, nos termos defendido por Ludke e André (1986), Gatti (2012) e Trivinõs (2008), entre outros, e utiliza como recurso analítico o levantamento e a análise de dados documentais. Dentre os documentos selecionados para a análise empírica estão o Referencial Curricular do Paraná: princípios, direitos e orientações, homologado em 2018 pelo estado do Paraná; o Referencial Curricular Gaúcho: Educação Infantil, homologado em 2018 pelo estado do Rio Grande do Sul; e o Currículo Base da Educação Infantil e do Ensino Fundamental do 
Território Catarinense, homologado em 2019 pelo estado de Santa Catarina. Esses documentos figuram como expressão do alinhamento entre a BNCC e as propostas curriculares dos sistemas estaduais de ensino da Região Sul.

Em atenção aos objetivos traçados, o texto inicia com uma breve exposição sobre formulações de governança considerando-se especialmente relações entre essas formulações e as políticas educacionais e curriculares que, no contexto contemporâneo, constituem o projeto da nova direita. Na sequência, são apresentados dados resultantes da análise dos documentos que informam as propostas curriculares dos sistemas estaduais de ensino da Região Sul e são produzidas inferências acerca das concepções de currículo (manifestas ou latentes) considerando-se as recontextualizações produzidas nesses documentos. Por fim, evidenciam-se responsabilidades adjudicadas às escolas de educação básica em consequência dos arranjos produzidos pelos sistemas estaduais, bem como desafios a serem enfrentados na materialização de um currículo que possa garantir o atendimento das funções sociais da educação.

\section{O discurso político-pedagógico dos aparelhos privados de hegemonia e os interesses do Movimento Todos pela Base Nacional Comum}

debate sobre os aparelhos privados de hegemonia não pode se dar descolado do tema da governança, posto que a atuação desses aparelhos cresce na mesma proporção em que o Estado passa a desenvolver estratégias mais complexas de regulação e controle da ação pública. As mudanças no ideário social-democrático de países que passaram recentemente por governos militares de cariz ditatorial vêm contribuindo para produzir novas relações com a sociedade civil.

Na educação, o discurso da gestão democrática contribuiu para a difusão da ideia de que a atuação do Estado se dá com participação de todos. Por essa lógica, o Estado não deixa de ser o responsável pela oferta de serviços, mas altera substancialmente suas funções, transferindo "[...] parte das tarefas de provimento dos serviços públicos a organizações não governamentais [...]" (SHIROMA; EVANGELISTA, 2014, p. 22). A participação de grupos sociais com interesses e compromissos diversos tem culminado na constituição de redes de governança da qual fazem parte aparelhos privados de 
Atuação dos aparelhos privados de hegemonia na implementação da BNCC nos estados da Região Sul

hegemonia unidos, de acordo com Ball (2014, p. 36), "[...] por subscrição de um conjunto discursivo, que circula dentro dessa rede de relações e é legitimado por ela".

No Brasil, o enfraquecimento do estado de exceção, que vigorou durante a ditadura civil-militar (1964-1984), abriu espaço para a redemocratização do país e a organização de mecanismos de participação da classe trabalhadora na decisão de políticas sociais nacionais e locais. Contudo, o movimento internacional que se erguia nos anos 1980 não passou despercebido pela burguesia brasileira que, conforme relata Casimiro (2018, p. 39), começou, ainda que de forma lenta e gradual, "[...] a reagir frente às formas de organização da classe trabalhadora" e a construir suas estratégias de como se relacionar com o Estado".

A reação das classes populares frente à redemocratização do País foi contida pela burguesia brasileira com a complexificação do padrão de dominação que, segundo Fontes (2010, p. 321), agregaria "[...] à autocracia burguesa e à truculência no trato social novas modalidades de convencimento". Como parte desse movimento, houve a necessidade de ajustes estruturais nas funções do Estado de modo a, ainda conforme a autora, adequar-se ao quadro atual do capitalismo internacional e à domesticação da democracia ao novo arranjo democrático.

As estratégias de dominação dos grupos que se avolumavam no Brasil tanto pela coerção como pelo convencimento, no final dos anos 1980 e início dos anos 1990, incluíam a formação de intelectuais coletivos para atuar na formulação de diretrizes de ação político-operacional e na proposição de políticas públicas para o Estado. Entre os temas centrais dos debates promovidos pelas organizações de ação política e ideológica que começavam a ganhar vulto no país, especialmente a partir da virada para o século XXI, sob a forma de aparelhos privados de hegemonia, estava a governança democrática e a educação. Contudo, nos debates travados em seminários, reuniões e encontros organizados por alguns desses aparelhos, a democracia era tratada como um conceito econômico e a educação como um produto em favor da competitividade internacional (APPLE, 2003).

Sob os auspícios do desenvolvimento da qualidade da educação básica, o Movimento Todos Pela Base Nacional Comum é exemplo de organização criada por aparelhos privados de hegemonia com a propensão de 
atuar na formulação de projetos de doutrinação educacional, na universalização dos interesses de classe como consenso e no realinhamento das bases de dominação do Estado (MARTINS, 2007). Trata-se de um grupo não governamental composto por instituições privadas e pessoas de diversos setores educacionais cuja finalidade explícita é assegurar a implantação da BNCC. Participam do MBNC a Fundação Lemann, o Instituto Inspirare, o Instituto Península, a Fundação Roberto Marinho, o Instituto Ayrton Senna, o Instituto Natura, o Instituto Unibanco, personalidades políticas, gestores educacionais, entre outros sujeitos individuais e coletivos, com interesses diversos .

Segundo consta em um documento publicado em novembro de 2015, pelo Centro de Estudos Educação \& Sociedade (Cedes), o Movimento foi formado a partir do Seminário Internacional Liderando Reformas Educacionais, ocorrido em 2013, nos Estados Unidos (CEDES, 2015). No grupo das instituições educacionais que compõem o Movimento estão: o Conselho Nacional de Secretários Estaduais de Educação (Consed); a União Nacional dos Dirigentes Municipais de Educação (Undime); o Conselho Nacional de Educação (CNE); - Conselho Estadual de Educação de São Paulo (CEE-SP); a Comissão de Educação da Câmara dos Deputados; e o Movimento Todos pela Educação (TPE). Contudo, o alcance do MBNC não se limita à implantação e implementação da BNCC. A organização também ałua na participação da definição e construção de políticas educacionais correlatas à Base.

Em face dos ideais de alguns grupos que fazem parte ou apoiam o Movimento (inclusive com recursos financeiros), Moreno (2016, p. 10) salienta que, "[...] além do propósito explícito de melhorar a qualidade da educação e os índices educacionais, duas grandes intenções podem ser inferidas da atuação do MBNC [...]" sobretudo pelo curso das ações empreendidas por seus membros e apoiadores antes, durante e após a homologação da BNCC.

As intenções implícitas do Movimento remetem a duas dimensões difusas da BNCC: uma doutrinária e outra tático-operacional. Essas intenções ficam melhor evidenciadas na contribuição que se espera que a BNCC ofereça

[...] para o alinhamento de outras políticas e ações, em âmbito federal, estadual e municipal, referentes à formação de professores, à avaliação, à elaboração de conteúdos educacionais e aos critérios para a oferta de infraestrutura adequada para o pleno desenvolvimento da educação (BRASIL, 2017, p. 8). 
Atuação dos aparelhos privados de hegemonia na implementação da BNCC nos estados da Região Sul

C conjunto de pessoas e instituições integrantes ou que oferecem apoio ao MBNC, na sua maioria constituído por sujeitos e entidades empresariais presentes também noutras organizações voltadas às reformas educacionais, notadamente no Todos Pela Educação, como demonstram estudos desenvolvidos por Caetano (2018), Bernardi, Uczak e Rossi (2018) e Rosa e Ferreira (2018), sintoniza-se com a causa de preparação de "intelectuais orgânicos do capital" (SHIROMA; CAMPOS; GARCIA, 201 1) a partir da formação dos conglomerados empresariais.

A presença de agentes políticos-pedagógicos, como a Associação Brasileira de Avaliação Educacional (Abave), o Centro de Estudos e Pesquisas em Educação, Cultura e Ação Comunitária (Cedac e Cenpec) e os prestadores de consultoria e assessoria pedagógica a secretarias de educação, e de agentes do Estado, entre eles o Consed, a Undime e indivíduos com assento nas estruturas do Estado, com "expertise técnica" e "esfera de influência" (NEVES; PICCININI, 2018, p. 191 e 194), situam o Movimento como uma "associação monopolista" de atuação tanto na esfera da produção para o mercado interno e externo como também na esfera política, dentro e através do Estado.

Ainda que os interesses dos grupos que compõem o MBNC possam ser 8 difusos, a depender dos setores nos quais atuam os indivíduos que dele fazem parte, as intenções implícitas concordam com as estratégias dos aparelhos privados de hegemonia, de produção e reprodução da ideologia dominante de modo a tornar hegemônicos valores sociais, culturais e econômicos da burguesia brasileira e produzir reformas estruturais.

\section{Implementação da BNCC pelas redes e sistemas de ensino brasileiros: 0 discurso oficial}

O prazo estipulado na Resolução CNE/CP n² 2/2017 para adequação dos currículos escolares à BNCC (no máximo, até o início do ano letivo de 2020) exigiu a mobilização imediata dos estados, municípios e instituições de ensino de todo o Brasil.

A implementação da BNCC pelas unidades da federação exigiu do governo federal um conjunto de providências tático-operacionais de modo a garantir um determinado alinhamento entre a BNCC, as propostas estaduais, as municipais e as das instituições de ensino. É importante mencionar que foi 
oportunizada aos municípios a adesão às propostas elaboradas no âmbito de cada estado da federação. A adesão à proposta estadual isentava o município de elaborar seu próprio documento curricular, valendo para o município, portanto, a proposta da rede estadual.

O conjunto de ações desenvolvidas pela União para garantir a implementação da política curricular informada pela BNCC, e reforçada pela ideia de uma base nacional comum, está alinhado com as estratégias de atuação do MBNC. Na plataforma da web do Movimento, estão disponíveis materiais, ferramentas, cursos gratuitos e orientações para implementação da BNCC nos currículos das redes de ensino brasileiras. O processo gestado, e em curso, se materializa por meio do ProBNCC que tem no regime de colaboração entre estados, Distrito Federal e municípios a garantia de sua formulação nos moldes do documento nacional.

Um levantamento realizado no sítio das secretarias estaduais de educação aponta que todos os estados da federação formalizaram a versão escrita do documento de suas redes de ensino até o final do ano de 2019. A pulverização de títulos atribuídos ao documento produzido pelas unidades da federação evidencia certa dificuldade das redes em determinar a característica central do documento. Ao que parece, a dúvida principal residiu em definir se ele seria uma referência, uma proposta ou o currículo propriamente dito.

Apesar da diversidade de títulos, é possível identificar três conjuntos de documentos. Um primeiro conjunto considera o documento produzido pelo estado como um referencial, uma base que deverá subsidiar a construção e revisão dos currículos pelas escolas. $\bigcirc$ segundo, define a proposta como o próprio currículo das redes estadual e municipal, cabendo à escola a tarefa de colocá-lo em prática. Por fim, um terceiro conjunto denomina-o de documento curricular. Essa nomenclatura, ambiguamente permite inferir que o documento pode se tratar de um referencial curricular, uma vez que menciona a incumbência das redes de ensino municipais e escolas de revisar e construir seus próprios currículos. Mas também permite compreender que se trata do currículo em si, posto que não há nenhuma menção sobre a tarefa das redes municipais e escolas em outros documentos com o mesmo título.

Uma análise global dos documentos, contudo, permite afirmar que a maioria dos estados definiu o documento como o currículo em si o que, em alguma medida, indica que este seria o roteiro oficial, o currículo prescrito, o 
Atuação dos aparelhos privados de hegemonia na implementação da BNCC nos estados da Região Sul

texto (BERSNTEIN, 1996), cabendo às escolas e seus professores interpretá-los e traduzi-los no contexto da prática curricular. Embora admita-se certo grau de autonomia dos professores na recontextualização do texto oficial para o contexto da prática não se pode perder de vista que, conforme procuramos demonstrar, a implementação da BNCC foi cuidadosamente orientada para constranger recontextualizações mais amplas. As ferramentas disponibilizadas pelo MBNC têm a função de tornar hegemônico o modelo curricular que a Base bafeja, favorecendo, desse modo, o alinhamento das políticas de formação de professores à BNCC.

\section{A implementação da BNCC pelos estados da Região Sul}

Os estados do Paraná e do Rio Grande do Sul aprovaram suas propostas curriculares no ano de 2018 e as intitularam, respectivamente, Referencial Curricular do Paraná e Referencial Curricular Gaúcho. Santa Catarina aprovou sua proposta em 2019 e, diferentemente dos demais estados sulinos, nomeou o documento de Currículo Base da Educação Infantil e do Ensino Fundamental do Território Catarinense.

A despeito das especificidades locais, um levantamento realizado nos documentos que conformam a proposta curricular desses estados permite evidenciar que os percursos e medidas adotadas no processo de implementação da BNCC possuem muito mais similitudes do que distanciamentos.

Um dos aspectos observados nessa direção refere-se às instituições que participaram dos processos de mobilização, elaboração e implementação da proposta. Nos três estados sulinos, a Comissão de implementação da proposta curricular contou com a participação de representantes das Secretarias de Estado da Educação; Undime; Conselhos Estaduais de Educação; e União Nacional dos Conselheiros Municipais de Educação (Uncme). Além dessas instituições, o Rio Grande do Sul e o Paraná incluíram representações de associações, sindicatos e movimentos sociais. $\bigcirc$ estado do Rio Grande do Sul incluiu, ainda, representantes do Ministério Público do Estado como parte da Comissão.

Na Portaria Ministerial que instituiu o ProBNCC, as instituições que integram a comissão estadual de elaboração da proposta e a equipe técnica de currículo e gestão constituem "a governança" da BNCC nos estados (BRASIL, 
2018 ). Trata-se, a nosso ver, do interesse de difundir a ideia de que a elaboração da proposta dos estados atende aos princípios de gestão democrática e participativa requeridos pela Lei de Diretrizes e Bases da Educação Nacional. Diz respeito, ainda, à produção de um discurso sobre o engajamento dos setores da sociedade civil na implementação da BNCC.

Conforme demonstrado, as redes de governança dão sustentação aos modos de governar e, atualmente, também participam da construção de projetos estruturais de mudança da ossatura do Estado. No tocante a esse aspecto, os estados do Rio Grande do Sul e do Paraná contaram com um conjunto bem mais expressivo de instituições do que o estado de Santa Catarina. Contudo, não se pode perder de vista que a coordenação do processo de formulação do currículo nos estados sulistas está centrada em apenas algumas instituições, tais como o Consed, e cuja coordenação é operada pelas Secretarias de Estado de Educação, Conselhos Estaduais de Educação, Undime e Uncme.

A presença de algumas dessas instituições, mormente da Undime e Uncme, nas comissões que atuaram na elaboração da BNCC indica a tendência à convergência de procedimentos, assim como a produção de consensos em torno do modelo de proposta, dada justamente a oportunidade desses atores em adquirir conhecimento da prática, do como fazer. Uma evidência da influência das experiências obtidas por essas instituições é a similaridade entre as estratégias e a sua convergência com a estratégia nacional, conforme pode ser observado na descrição dos procedimentos de cada estado.

\section{A implementação da BNCC no Rio Grande do Sul}

Oestado do Rio Grande do Sul iniciou a construção da sua proposta curricular no ano de 2018 e estabeleceu um regime de colaboração entre estado, municípios e escolas pertencentes à rede privada.

Os profissionais da educação participaram do processo por meio de uma plataforma virtual. Segundo a declaração no Referencial Curricular Gaúcho (2018), foram realizadas duas consultas públicas por via dessa ferramenta. As contribuições recebidas foram sistematizadas por redatores e coordenadores de cada uma das etapas da educação básica leducação infantil, anos iniciais do ensino fundamental e anos finais do ensino fundamentall. Tais redatores representavam o Consed, o Seduc e a Undime. Segundo 
Atuação dos aparelhos privados de hegemonia na implementação da BNCC nos estados da Região Sul

informações disponíveis nessa plataforma, foram recebidas mais de 120 (cento e vinte mil) contribuições.

Após a sistematização das contribuições, uma Conferência Estadual foi realizada na capital do estado, com vistas a validar a proposta. $\bigcirc$ documento foi homologado pelo Conselho Estadual de Educação em 12 de dezembro do ano de 2018.

O Referencial Curricular Gaúcho (RCG) está estruturado em seis cadernos pedagógicos, sendo um para a educação infantil e os demais organizados por áreas do conhecimento, quer sejam: linguagens, matemática, ciências da natureza, ciências humanas e ensino religioso. Observa-se grande semelhança com o documento nacional, inclusive na definição das competências gerais e específicas, que seguem ipsis verbis a BNCC. Um aspecto interessante do RCG é que tanto na educação infantil como no ensino fundamental foram acrescidos objetivos de aprendizagem e habilidades específicas do estado, identificados por um código alfanumérico. A despeito dessa distinção, é possível constatar que eles não destoam dos objetos listados no documento nacional, ou seja, não há transbordamento importante em relação à BNCC.

Evidenciamos, na análise geral do documento, preocupação com um documento que atendesse a algumas especificidades da realidade do estado. Essa evidência é reforçada pela delimitação de um quadro teórico de sustentação da proposta. Consoante pode ser lido no documento, o RCG tem como função ser "[...] um balizador para a construção dos currículos nas escolas de diferentes esferas do Rio Grande do Sul [...], cabendo aos sistemas e redes de ensino e até mesmo às escolas privadas [...] a construção de documento orientador, viabilizando as peculiaridades locais [...]" (RIO GRANDE DO SUL, 2018 , p. 19). Ou seja, a construção do currículo ficará como incumbência das unidades escolares, haja vista a necessidade em incluir a parte diversificada, exigida pelas características locais em que a instituição está inserida. Não obstante, a referência será o documento estadual.

\section{A implementação da BNCC no Estado de Santa Catarina}

Santa Catarina iniciou a construção de seu documento no ano de 2018 por meio das seguintes ações: elaboração e execução do plano de ações, alinhado às orientações do MEC; constituição da Comissão Estratégica 
e Comissão Executiva de Mobilização para Implementação da BNCC; seleção do grupo de redatores e de 540 (quinhentos e quarenta) profissionais das redes públicas estadual e municipal para participar do processo de elaboração e implementação do currículo catarinense; pré-seleção de 35 (trinta e cinco) consultores; elaboração da proposta inicial do documento; criação de um ambiente virtual, com vistas a disponibilizar a proposta inicial para que os profissionais da educação pudessem contribuir na definição do conteúdo do documento; sistematização das contribuições, resultando na primeira versão do documento.

No ano de 2019, em função da troca de governo no estado, foram reestruturadas a Comissão Estratégica e a Comissão Executiva de Mobilização para Implementação da BNCC. A proposta foi aprovada pelo Conselho Estadual de Educação (CEE) de Santa Catariana em 17 de junho de 2019.

O documento Currículo Base da Educação Infantil e do Ensino Fundamental do Território Catarinense apresenta algumas especificidades em relação ao nacional. A primeira delas refere-se ao esforço dos redatores do documento em demonstrar que este foi resultado de um processo democrático e que, por isso, preserva as características das escolhas efetuadas coletivamente, conforme pode ser lido e observado em várias passagens do documento. $\bigcirc$ resultado desse processo é a estruturação do documento, especialmente na parte em que se refere às áreas de conhecimento, posto que não há uma padronização nos itens e na explicitação sobre a composição de cada área.

A segunda especificidade do documento catarinense refere-se ao fato de se procurar garantir certo alinhamento com a Proposta Curricular de Santa Catarina (PCSC), cuja versão atual foi elaborada em 2014. A tentativa de alinhamento com a PCSC é demonstrada em várias passagens do documento. Uma delas é a definição de como deve ser compreendido o percurso formativo e o processo de aquisição do conhecimento escolar das crianças e jovens catarinenses, demonstrado por uma figura em espiral.

A tentativa de aproximação com a PCSC também está evidenciada na afirmação da diversidade como princípio formativo, o que implica tomar esse tema em sua dimensão pedagógica e transversal. No documento, há um espaço inicial reservado ao tratamento do que seus redatores consideram "[...] algumas compreensões fundamentais" sobre o tema (SANTA CATARINA, 20 19b, p. 211. 
Atuação dos aparelhos privados de hegemonia na implementação da BNCC nos estados da Região Sul

Por fim, um último aspecto que demarca o conjunto das especificidades do documento catarinense em relação ao da BNCC é o que se refere ao processo de alfabetização e letramento. Um dos grupos que atuou na formulação do documento dedicou-se ao tema da alfabetização em articulação com as práticas de linguagem.

A despeito dessas especificidades, o Currículo Base da Educação Infantil e do Ensino Fundamental do Território Catarinense apresenta as mesmas competências gerais e específicas da BNCC, assim como as mesmas áreas de conhecimento e componentes curriculares. A parte em que se refere à educação infantil também segue a estrutura do documento nacional, ou seja, está organizada em direitos de aprendizagem, campos de experiência e objetivos de aprendizagem e desenvolvimento.

Não obstante, por ter sido organizada de acordo com as especificidades de cada grupo de redatores e de profissionais que atuaram na revisão do documento, não há uma estrutura organizacional única na apresentação dos componentes curriculares.

Os municípios catarinenses com sistema próprio de ensino tiveram a opção de aderir ao Currículo Base da Educação Infantil e do Ensino 14 Fundamental do Território Catarinense ou construir o seu próprio documento. As escolas tiveram a atribuição de adequar os projetos político-pedagógicos ao documento base, nomeadamente no que tange ao trabalho envolvendo os temas transversais contemporâneos.

Os municípios catarinenses que não possuem seus sistemas próprios de ensino instituídos em forma de Lei deverão realizar a adesão ao documento do estado (SANTA CATARINA, 2019a). $O$ processo de adesão ao currículo catarinense está sendo monitorado pelo Conselho Estadual de Educação. Um aspecto interessante é que os municípios que optarem por construir seu próprio documento, apesar de ter sistema de ensino, deverão encaminhar o documento ao CEE/SC para aprovação. Essa medida permite constatar que a relação que se estabelece entre estado e município é de submissão e não de colaboração entre os dois entes federativos (estado e município), ao menos em relação aos currículos escolares. 


\section{A implementação da BNCC no Estado do Paraná}

Para a elaboração de sua proposta curricular com base na BNCC, o estado do Paraná instituiu um comitê executivo e uma assessoria técnica. A versão preliminar da proposta curricular foi elaborada por uma equipe de redatores indicados por esses dois grupos. Em junho de 2018, a versão preliminar foi disponibilizada para consulta pública por um período de 30 dias. Segundo consta no documento paranaense professores e gestores tiveram a oportunidade de estudar, discutir e sugerir contribuições ao documento durante o segundo semestre de 2018 . Após a sistematização das contribuições advindas da consulta pública, o documento foi encaminhado para o Conselho Estadual de Educação para apreciação e homologação (PARANÁ, 2018).

No Referencial Curricular do Paraná (RCP), aprovado em 2018 , constam como princípios orientadores da proposta curricular: educação como direito inalienável de todos os cidadãos; prática fundamentada na realidade dos sujeitos da escola; igualdade e equidade; compromisso com a formação integral; valorização à diversidade; educação inclusiva; transição entre as etapas e fases da educação básica; ressignificação dos tempos e espaços da escola; e avaliação como momento de aprendizagem (PARANÁ, 2018).

Os organizadores curriculares da educação infantil são compostos por seis partes correspondentes às idades das crianças. Nesse aspecto, a proposta paranaense transborda a divisão apresentada na BNCC . Para cada idade, são apresentados os mesmos campos de experiências e objetivos de aprendizagem definidos pela BNCC.

No ensino fundamental, os componentes curriculares de $1^{\circ}$ ao $9^{\circ}$ ano apresentam unidades temáticas, objetos do conhecimento e objetivos de aprendizagem. Talvez o aspecto que mais mereça atenção nessa proposta em relação à BNCC é o fato de o documento paranaense não adotar a terminologia das competências gerais e específicas. No seu lugar, os organizadores da proposta preferiram utilizar a expressão direitos de aprendizagem, utilizada na primeira versão do documento nacional. No lugar da expressão habilidades, aparece o termo objetivos de aprendizagem. Um conjunto de objetivos distintos da relação de habilidades constante na BNCC é apontado no documento (PARANÁ, 2018). 
Atuação dos aparelhos privados de hegemonia na implementação da BNCC nos estados da Região Sul

Esse transbordamento de termos em relação à BNCC pode estar relacionado às críticas que recaem sobre a noção de competência na literatura produzida pela área da educação (ROPÉ, TANGUY, 1997; LOPES, MACEDO, 2002a, 2002b; RAMOS, 2001; SANTOMÉ, 1998 - entre outros). A primazia das competências sobre os conhecimentos assumiu relevância na década de 1990, aliada à ideia de um savoir-faire. Os críticos do currículo têm combatido a ideia porquanto atribui valor utilitário e instrumental aos conteúdos de ensino. Nessa direção, os conhecimentos escolares a serem valorizados seriam aqueles úteis ao desenvolvimento de aptidões laborais.

documento do estado do Paraná constitui-se como referência para a elaboração das propostas curriculares e dos projetos político-pedagógicos das escolas. Como nos demais estados da Região, há que se atentar para a necessária mobilização das equipes pedagógicas das instituições de ensino no sentido de elaborar ou revisar suas propostas à luz do documento do estado.

Como é possível verificar, os três estados sulinos remeteram às escolas e redes de ensino a tarefa de materialização do currículo segundo as demandas da BNCC. Recai, portanto, sobre a gestão e os docentes a responsabilidade de operacionalizar a BNCC do ponto de vista da materialidade curricular. Se 16 considerarmos as estratégias montadas pela União e seus aparelhos privados de hegemonia para promover constrangimento na recontextualização do documento nacional há de se admitir que prevaleceu a reprodução do texto oficial nas propostas curriculares sulinas.

Na esteira de Bernstein (1996), compreendemos que as estratégias de controle adotadas pelo Estado quando da formulação das regras de implementação da BNCC culminaram na legitimação do texto oficial constrangendo e inibindo, portanto, recontextualizações mais amplas do discurso oficial. Ainda que tenhamos observado, algumas iniciativas recontextualizadoras, no seu conjunto prevaleceu a adaptação e o conformismo ao discurso pedagógico oficial.

\section{Considerações finais}

A evidência das estratégias adotadas pela União para coibir e controlar as recontextualizações do discurso oficial põe em evidência as relações de poder que se estabelecem na busca pela padronização de saberes 
considerados válidos para a educação básica e de como eles devem ser abordados pelas escolas e seus docentes. Evidencia, ainda, o poder hegemônico da nova direita brasileira para tornar a pactuação interfederativa o grande agente de mobilização na implementação da ideologia curricular dominante.

A nosso ver, os interesses ideológico e tático-operacional dos apareIhos privados de hegemonia que, num movimento difuso, porém bem articulado em defesa da BNCC, justificam a mobilização nacional de grupos com distintas motivações em torno da implementação da Base foram assegurados no processo desenvolvido pelos estados, haja vista a representatividade nacional dos indivíduos que compuseram as comissões estaduais. Nos estados da Região Sul, destaca-se a presença de representantes do Consed, do CEE, da Undime e da Ucme que, além de fazerem parte do Movimento Todos pela Base Nacional Comum, também constituíram as comissões nacionais de elaboração da BNCC atuando, assim, como agentes de legitimação do texto oficial perante às secretarias estaduais de educação.

Essas instituições figuram como importantes aparelhos de produção e disseminação do discurso oficial em torno da BNCC, uma vez que assumiram funções estratégicas nas comissões estaduais, de modo a assegurar alinhamento da proposta estadual com a nacional. É por isso que, a nosso ver, essas entidades figuraram como representantes dos aparelhos privados de hegemonia no âmbito local com uma atuação fundamental na produção de mecanismos favoráveis à adesão dos municípios ao documento elaborado pelos estados.

Na contramão desse processo, destacam-se os estados do Rio Grande do Sul e do Paraná que, ao menos no plano da representatividade, abriram espaço para a participação de um número maior de instituições em relação aos demais estados sulinos. Contudo, ainda que a participação da sociedade civil nas comissões criadas pelo estado gaúcho possa ter aberto espaços para recontextualizações mais amplas do documento nacional, a arquitetura edificada pelos aparelhos de hegemonia e os arranjos produzidos em torno da padronização do modelo do MBNC torna duvidosa a possibilidade de resistências ao discurso oficial.

Resta depositar expectativas nas escolas de educação básica que, a nosso ver, não constituem somente espaço de reprodução da ideologia dominante, senão também espaço legítimo de produção de ideias 
contra-hegemônicas. Suplantar o modelo de currículo imposto pela BNCC implica capacidade para reinterpretar criticamente o modelo hegemônico e reconstruir o texto oficial a partir de outras bases epistemológicas. Entretanto, isso somente será possível se não perdermos de vista que a escola é um local privilegiado para a produção de saberes e que os conteúdos de ensino devem servir para mediar conhecimentos que permitam aos educandos compreender e transformar o mundo.

Trata-se, pois, de um grande desafio para as escolas, haja vista o modus operandi de construção e implementação das propostas curriculares em curso no Brasil. Como procuramos demonstrar ao longo do texto, a BNCC tem seu foco nas demandas do modelo econômico em voga. A par disso está o anúncio do necessário alinhamento entre a política de avaliação da educação básica, os materiais didáticos, a formação de professores e os programas das esferas governos federais, estaduais e municipais. Romper com esses constrangimentos significa, portanto, caminhar no revés da BNCC.

\section{Notas}

1 A necessidade de uma Base Nacional Comum Curricular para todas as escolas de educação básica do Brasil não foi uma decisão consensual entre o Estado e a sociedade civil. Conforme demonstram Schneider e Nardi (2018), "[...] a BNCC é fruto de um processo longo, controverso e contestado por segmentos tão profusos quanto aqueles que a aprovaram".

2 A primeira versão da BNCC foi disponibilizada para consulta pública em outubro de 2015 . Em maio de 2016 , uma segunda versão foi disponibilizada pelo. A versão final foi aprovada em dezembro de 2017.

3 Bernstein (1996) desenvolveu o conceito de recontextulização para referir-se aos dispositivos pedagógicos que regulam simbolicamente o discurso educacional produzido e reproduzido em contextos distintos.

4 A participação de certos APH, tais como os que integram o Movimento Todos pela Base Nacional Comum, têm possibilitado, além da construção de uma hegemonia discursiva em torno da BNCC, a abertura de "[...] nichos de mercado para as iniciativas empresariais na educação" (SHIROMA; EVANGELISTA, 2014, p. 34).

5 Na matéria do blog de Luiz Carlos de Freitas, publicada em 26 de julho de 2015, consta que um seminário com o mesmo nome, promovido pela Universidade de Yale (USA) e pela Fundação Lemann, teria ocorrido em São Paulo no mês de abril do mesmo ano (FREITAS, 20 15).

6 A BNCC organiza a educação infantil em três grupos etários, quais sejam: bebês, crianças bem pequenas e crianças pequenas. 


\section{Referências}

APPLE, Michael Whitman. Educação e poder. Tradução Maria Cristina Monteiro. Porto Alegre: Artes Médicas, 1989.

APPLE, Michael Whitman. Educando à direita: mercados, padrões, Deus e desigualdade. Tradução Dinah de Abreu Azevedo. 5. ed. São Paulo: Editora Cortez/ Instituto Paulo Freire, 2003.

APPLE, Michael Whitman. Ideologia e currículo. Tradução Vinicius Figueira. 3. ed. Porto Alegre: Artmed, 2006.

APPLE, Michael. Whitman. BURAS, Kristen L. (org.). Currículo, poder e lutas educacionais: com a palavra, os subalternos. Tradução Ronaldo Catado Costa. Porto Alegre: Artmed, 2008.

APPLE, Michael Whitman. A luta pela democracia na educação crítica. Revista e-Curriculum, São Paulo, v. 15, n. 4, p. 894-926, out./dez. 2017.

BALL, Stephen J. Educação Global S.A.: novas redes políticas e o imaginário neoliberal. Tradução Janete Bridon. Ponta Grossa: UEPG, 2014.

BERNARDI, Liane Maria; UCZAK, Lucia Hugo; ROSSI, Alexandre José. Relações do movimento empresarial na política educacional brasileira: a discussão da Base Nacional Comum.

Currículo sem Fronteiras, v. 18, n. 1, p. 29-51, jan./abr. 2018.

BERNSTEIN, Basil. A estrutura do discurso pedagógico: classes, códigos e controle. Tradução Tomaz Tadeu da Silva e Luiz Fernando Gonçalves Pereira, Petrópolis: Vozes, 1996.

BIANCHI, Alvaro. O laboratório de Gramsci. Filosofia, História e Política. São Paulo: Alameda, 2008.

BRASIL. Resolução CNE/CP n 2, de 22 de dezembro de 2017. Institui e orienta a implantação da Base Nacional Comum Curricular, a ser respeitada obrigatoriamente ao longo das etapas e respectivas modalidades no âmbito da Educação Básica. Diário Oficial da União, Brasília, DF, 22 dez. 2017, Seção 1, Disponível em: http://basenacionalcomum.mec.gov. br/images/historico/resolucaocne_cp222dedezembrode2017.pdf. Acesso em: 26 jan. 2020.

BRASIL. Portaria n ${ }^{\circ} 331$, de 5 de abril de 2018. Institui o Programa de Apoio à Implementação da Base Nacional Comum Curricular - ProBNCC e estabelece diretrizes, parâmetros e critérios para sua implementação. Diário Oficial da União, Brasília, DF, 6 abr. 2018, Seção 1. Disponível em: http://www.in.gov.br/materia//asset_publisher/KujrwOTZC2Mb/ 
Atuação dos aparelhos privados de hegemonia na implementação da BNCC nos estados da Região Sul

content/id/9362390/do 1-20 18-04-06-portaria-n-328-de-5-de-abril-de-20 1 8-9362386. Acesso em: 28 jan. 2020.

BUCCI-GLUKSMANN, Cristiane. Gramsci e o Estado. Rio de Janeiro, Paz e Terra, 1980.

CAETANO, Maria Raquel. A educação no contexto de crise do capital e as relações entre estado, mercado e terceiro setor nas políticas educacionais. Laplage em Revista, Sorocaba, v. 4, n. 2, p. 153-168, maio/ago. 2018.

CASIMIRO, Flávio Henrique Calheiros. A nova direita: aparelhos de ação política e ideológica no Brasil contemporâneo. São Paulo: Expressão Popular, 2018.

CEDES. Centro de Estudos Educação e Sociedade. Documento Cedes BNCC, novembro 2015. Disponível em: www.cedes.unicamp.br. Acesso em: 20 jan. 2020.

FONTES, Virgínia. O Brasil e o capital-imperialismo. Rio de Janeiro: Ministério da Saúde/ Fundação Oswaldo Cruz: Escola Politécnica de Saúde Joaquim Venâncio, 2010.

FREITAS, Luiz Carlos de. Reformadores e base nacional: personagens. Blog do Freitas, Campinas, 26jul. 2015. Disponívelem: https:/ / avaliacaoeducacional.com/2015/07/26/ reformadores-e-base-nacional-personagens-i. Acesso em: 25 jan. 2020.

GANDIN, Luís Armando; LIMA, lana Gomes de. A perspectiva de Michael Apple para os estudos das políticas educacionais. Educação e Pesquisa, São Paulo, v. 42, n. 3, p. 651 664, jul./set. 2016.

GATTI, Bernardete Angelina. A construção da Pesquisa em Educação no Brasil. Brasília: Liber Livro, 2012.

GOODSON, Ivor Frederick. A construção social do currículo. Tradução Maria João Carvalho. Lisboa: Educa, 1997.

GOODSON, Ivor Frederick. A crise da mudança curricular: algumas advertências sobre iniciativas de reestruturação. In: SILVA, Luís Heron da (org.). Século XXI: qual conhecimento? qual currículo? Petrópolis: Vozes, 1999.

GOODSON, Ivor Frederick. Currículo, narrativa e o futuro social. Revista Brasileira de Educação, Rio de Janeiro, v. 12, n. 35, p. 241-252, maio/ago. 2007.

GOODSON, Ivor Frederick. Currículo: teoria e história. Tradução Attílio Brunetta. 9. ed. Petrópolis: Vozes, 2010.

HOEVELER, Rejane Carolina. $O$ conceito de aparelho privado de hegemonia e seus usos para a pesquisa histórica. Revista Práxis e Hegemonia Popular, Marília, v. 4, n. 5, p. 145 -159, ago./dez. 2019.

LIGUORI, Guido. Roteiros para Gramsci. Rio de Janeiro: Editora UFRJ, 2007. 
LOPES, Alice Casimiro; MACEDO, Elizabeth (org.). Disciplinas e integração curricular: histórias e políticas. Rio de Janeiro: DP\&A, 2002a.

LOPES, Alice Casimiro; MACEDO, Elizabeth (org.). Currículo: debates contemporâneos. São Paulo: Cortez, 2002b.

LOPES, Alice Casimiro; MACEDO, Elizabeth. Teorias de currículo. São Paulo: Cortez, 2011.

LUDKE, Menga; ANDRÉ, Marli Eliza Dalmazo Afonso de. Pesquisa em educação: abordagens qualitativas. São Paulo: EPU, 1986.

MARTINS, André Silva. Burguesia e a nova sociabilidade: estratégias para educar o consenso no Brasil contemporâneo. 2007. Tese (Doutorado em Educação) - Programa de Pós-Graduação em Educação da Universidade Federal Fluminense, 2007.

MENDONÇA, Sonia Regina de. O Estado ampliado como ferramenta metodológica. Marx e o Marxismo, v. 2, n. 2, jan./jul. 2014.

MORENO, Jean Carlos. História na Base Nacional Comum Curricular: Déjà vu e novos dilemas no século XXI. História \& Ensino, Londrina, v. 22, n. 1, p. 7-27, jan./jun. 2016.

NEVES, Rosa Maria Correa das; PICCININI, Cláudia Lino. Crítica do imperialismo e da Reforma curricular brasileira da educação básica: evidência histórica da impossibilidade da luta pela emancipação da classe trabalhadora desde a escola do Estado. Germinal: marxismo e educação em debate, Salvador, v. 10, n. 1, p. 184-206, maio 2008.

PACHECO, José Augusto. Estudos curriculares: para a compreensão crítica da educação. Porto: Porto Editora, 2005.

PARANÁ. Referencial Curricular do Paraná: princípios, direitos e orientações. Consed; Undime, 2018.

POPKEWITZ, Thomas S. Políticas Educativas e curriculares: abordagens sociológicas críticas. Tradução Joao M. Paraskeva. Mangualde-PO: Pedago, 2011.

RAMOS, Marise Nogueira. A pedagogia das competências: autonomia ou adaptação? São Paulo: Cortez, 2001.

RIO GRANDE DO SUL. Referencial Curricular Gaúcho: Educação Infantil. Porto Alegre: Secretaria de Estado da Educação, Departamento Pedagógico, 2018.

ROPÉ, Françoise, TANGUY, Lucie (org.). Saberes e competências: o uso de tais noções na empresa e na escola. Tradução Patrícia Chittoni Ramos e equipe. Campinas: Papirus, 1997. SANTOMÉ, Jurjo Torres. Globalização e interdisciplinaridade: o currículo integrado. Porto Alegre: Artmed, 1998. 
ROSA, Luciane Oliveira da; FERREIRA, Valéria Silva. A rede do movimento pela base e sua influência na Base Nacional Comum Curricular brasileira. Revista Teoria e Prática da Educação, Maringá, v. 21 , n. 2, p. 115-130, maio/ago. 2018.

SANTA CATARINA. Conselho Estadual de Educação. Resolução $\mathbf{n}^{\circ} \mathbf{0 7 0}$, de 17 de junho de 2019. Institui e orienta a implementação do Currículo Base da Educação Infantil e do Ensino Fundamental do Território Catarinense e normatiza a adequação à Base Nacional Comum Curricular dos currículos e propostas pedagógicas da Educação Infantil e do Ensino Fundamental no âmbito do Sistema Estadual de Educação de Santa Catarina. Florianópolis: Conselho Estadual de Educação, 2019a.

SANTA CATARINA. Currículo Base da Educação Infantil e do Ensino Fundamental do Território Catarinense. Florianópolis: Secretaria de Estado da Educação. Diretoria de Planejamento e Políticas Educacionais. Gerência de Políticas Educacionais, 2019b.

SCHNEIDER, Marilda Pasqual; NARDI, Elton Luiz. Pilares estruturantes da Base Nacional Comum Curricular da Educação Brasileira: subordinação à agenda global. Revista de Estudos Curriculares, Braga, n. 9, v. p. 45-61, 2018.

SHIROMA, Eneida Oto; Campos, Roselane Fátima; Garcia, Rosalba Maria Cardoso. Decifrar textos para compreender a política: subsídios teórico-metodológicos para análise de documentos. Perspectiva, Florianópolis, v. 23, n. 2, p. 427-446, jul./dez. 2005.

SHIROMA, Eneida Oto; Campos, Roselane Fátima; Garcia, Rosalba Maria Cardoso. Conversão das "almas" pela liturgia da palavra: uma análise do movimento Todos pela Educação. In: BALL, Stephen J.; MAINARDES, Jefferson. Políticas educacionais: questões e dilemas. São Paulo: Cortez, 2011.

SHIROMA, Eneida Oto; EVANGELISTA, Olinda. Estado, capital e educação: reflexões sobre a hegemonia e redes de governança. Revista Educação e Fronteiras On-Line, Dourados, v. 4, n. 11, p. 21-38, maio/ago. 2014.

SILVA, Tomaz Tadeu da. Documentos de Identidade: uma introdução às teorias do currículo. 2. ed. Belo Horizonte: Autêntica, 2002.

TRIVIÑOS, Augusto Nibaldo Silva. Introdução à pesquisa em ciências sociais: a pesquisa qualitativa em educação. São Paulo: Atlas, 2008. 
Profa. Dra. Marilda Pasqual Schneider Universidade do Oeste de Santa Catarina (Brasil) Programa de Pós-Graduação em Educação Investigadora convidada do Instituto Interuniversitario de Investigación Educativa (Chile)

Diretora da Associação Nacional de Política e Administração da Educação (Santa Catarina)

Editora-chefe da revista Roteiro (Unoesc) e editora-associada da Revista de Educação da Pontifícia Universidade Católica de Campinas Líder do Grupo de Estudos e Pesquisas em Políiticas de Avaliação Educacional e Accountability em países da América Latina Orcid id: https: / / orcid.org/0000-0003-3019-008X E-mail: marilda.schneider@unoesc.edu.br

Profa. Dra. Camila Regina Rostirola Universidade do Oeste de Santa Catarina (Brasil) Programa de Pós-Graduação em Educação Editora-Chefe da Revista Roteiro (Unoesc) Coordenadora Institucional do Programa Institucional de Bolsas de Iniciação à Docência (Pibid) na Unoesc Grupo de Pesquisa Educação, Políticas Públicas e Cidadania Orcid id: https:/ / orcid.org/0000-000 1-8280-8879 E-mail: camila.rostirola@unoesc.edu.br Recebido 5 jun. 2021 Aceito 26 jul. 2021 